\title{
CAPACIDADE DE RETENÇÃO DE ÁGUA EM SOLOS DA SERRA DO MAR, SP
}

\author{
Rodolfo Moreda MENDES \\ Fernando Antônio Medeiros MARINHO \\ Mario VALÉRIO FILHO
}

\begin{abstract}
RESUMO
Apresenta-se um estudo comparativo entre as características físicas, mineralógicas e microestruturais e as curvas de retenção de água de horizontes representativos de dois perfis de solo (Cambissolos Háplicos distróficos) da Serra do Mar. As curvas de retenção de água foram obtidas por três métodos: placa de sucção (para tensões de 1 a $30 \mathrm{kPa}$ ); câmara de pressão (para tensões de 50 a $400 \mathrm{kPa}$ ) e papel filtro (para tensões acima de $400 \mathrm{kPa}$ ). Em geral, os solos estudados apresentam relativa homogeneidade mineralógica e significativa heterogeneidade microestrutural e textural. Essa heterogeneidade afeta diretamente o formato das curvas de retenção de água obtido para a maioria dos solos, podendo, inclusive, influenciar positiva ou negativamente o comportamento da condutividade hidráulica. Na prática, a maior ou menor condutividade hidráulica dos horizontes de solo influenciará diretamente na capacidade de infiltração da água da chuva e, consequentemente, no fator de segurança ou de estabilidade das encostas em áreas de risco. Merece ser destacado que o comportamento de retenção de água não está relacionado exclusivamente com as características mineralógicas e texturais do solo, mas também com os aspectos microestruturais do solo, por meio da distribuição de macro e microporos em seu arcabouço.
\end{abstract}

Palavras-chave: perfis de alteração, curvas de retenção de água, condutividade hidráulica.

\section{ABSTRACT}

WATER RETENTION CAPACITY IN SOILS OF THE SERRA DO MAR, SP. A comparative study of the physical, mineralogical and microstructural properties and the soil-water retention curves of representative soil horizons of two weathering profiles (dystrophic Haplic Cambisols) of the Serra do Mar are presented here. The soil-water retention curves were obtained using three methods: suction plate (for suctions from 1 to $30 \mathrm{kPa}$ ); chamber of pressure (for suctions from 50 to 400 $\mathrm{kPa}$ ), and filter paper (for suctions above $400 \mathrm{kPa}$ ). In general, the soils showed relative mineralogical homogeneity and a significant microstructural and textural heterogeneity. This heterogeneity directly affects the shape of the soil-water retention curves obtained for most soils, and may also (positively or negatively) influence the behavior of the hydraulic conductivity. In practice, changes in the hydraulic conductivity of soil layers will greatly influence the rainwater infiltration capacity, and hence the factor of safety or stability of the slopes in areas at risk. It is important to emphasize that the water retention behavior is not exclusively related to the mineralogical and textural characteristics of the soil, but also to microstructural features of the soil, such as soil macro and micropore distribution.

Keywords: weathering profiles, soil-water retention curve, hydraulic conductivity. 


\section{INTRODUÇÃO}

O conhecimento da variabilidade espacial das propriedades físico-hídricas dos solos é importante para a melhor compreensão da dinâmica do fluxo de água nos diferentes perfis de solo, podendo ser diretamente aplicada em diversas áreas do conhecimento, tais como agricultura de precisão, geotecnia, entre outras (e.g. OTTO \& ALCAIDE 2001, COOPER et al. 2013). Dentre as propriedades físico-hídricas, as obtidas por meio da curva de retenção de água no solo (CRA) são extremamente importantes em estudos que visam melhorar o entendimento da influência do escoamento e/ou infiltração da água da chuva em processos erosivos e deslizamentos de encostas (MORAES et al. 1993, FREDLUND \& RAHARDJO 1993). A curva de retenção de água (CRA) ou curva característica solo-água expressa a relação entre a quantidade de água retida no solo e a sucção matricial. A quantidade de água pode ser representada pelo teor de umidade gravimétrico, volumétrico ou pelo grau de saturação do solo.

A retenção de água no solo é afetada por algumas características dos solos, tais como: estrutura, tamanho e geometria dos poros, textura e mineralogia (MORAES et al. 1993). Em relação à textura, observa-se que para solos argilosos o desenvolvimento da sucção é maior do que para solos mais arenosos, pois os primeiros tendem a reter mais água para certo valor de sucção, devido principalmente aos seus aspectos macro e microestruturais (FREDLUND \& XING 1994). Em relação à estrutura e distribuição de poros, observa-se que para solos com maior proporção de macroporos e estrutura granular existe uma tendência de maior drenagem e, portanto, menor retenção de água principalmente para baixos potenciais hídricos (COOPER et al. 2013).

Alguns estudos tem buscado estabelecer relações entre as características físicas e o movimento da água nos solos por meio da descrição pedológica. No entanto, na maioria das vezes, as propriedades hidráulicas não coincidem com os horizontes pedológicos ao longo de um perfil de solo, pois as características utilizadas na separação dos horizontes não contemplam aspectos mineralógicos e microestruturais dos solos (MARQUES et al. 2002).

Neste contexto, o presente trabalho mostra um estudo comparativo entre as características físicas, mineralógicas, microestruturais e as propriedades hidráulicas das curvas de retenção de água de dois perfis de solo residual típicos da Serra do Mar.

\section{MATERIAIS E MÉTODOS}

As amostras deformadas e indeformadas de solo utilizadas no presente trabalho foram coletadas ao longo de dois taludes verticais em duas encostas naturais da Serra do Mar, parcialmente degradadas por mineração de saibro, nos bairros Maranduba ( $45^{\circ} 14^{\prime} \mathrm{W}$; $23^{\circ} 32^{\prime} \mathrm{S}$; $35 \mathrm{~m}$ ) e PerequêMirim (45 $06^{\prime} \mathrm{W} ; 23^{\circ} 28^{\prime} \mathrm{S}$; $60 \mathrm{~m}$ ), situados no Município de Ubatuba/SP (Figura 1). Esses solos são classificados como Cambissolos Háplicos distróficos segundo o Sistema Brasileiro de Classificação de Solos (EMBRAPA 2013). Eles apresentam horizonte constituído por rocha parcialmente intemperizada ("saprolito"), com significativo estágio de intemperismo, sendo, portanto de consistência branda. Pelo fato de serem relativamente pouco evoluídos, os Cambissolos apresentam em geral significativos teores de minerais primários facilmente intemperizáveis.
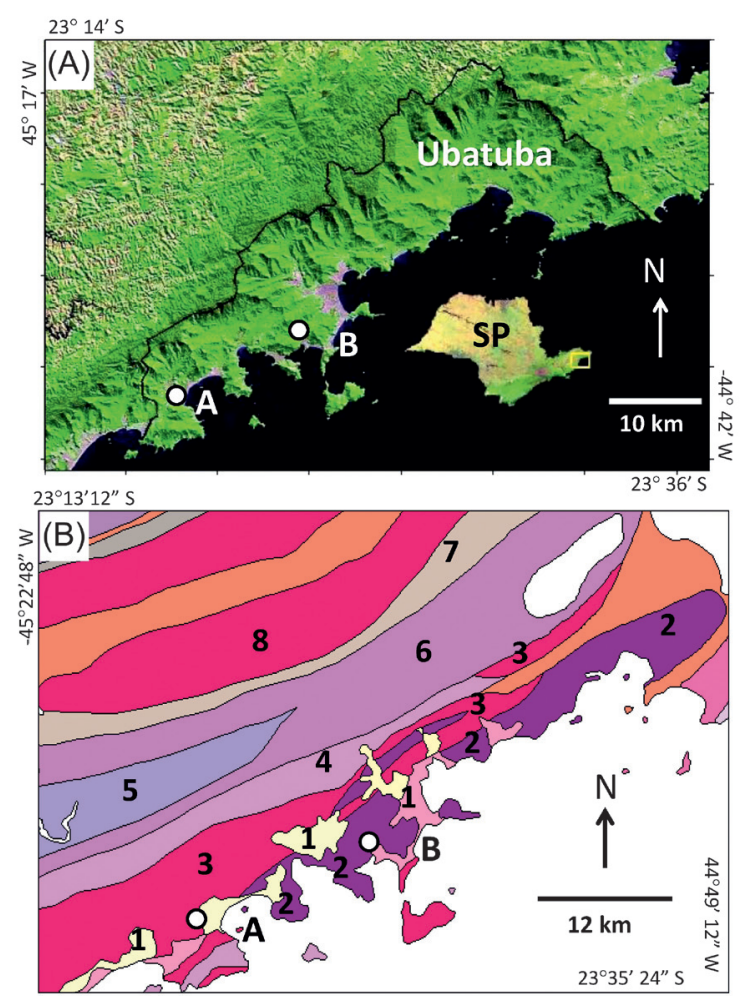

UNIDADES LITO-ESTRATIGRÁFICAS
1- Coberturas Sedimentares
2- Charnockito Ubatuba
3- Biotita Granito
5- Biotita gnaisses
6- Migmatitos
7- Quatzitos
4- Biotita migmatito/granito-gnaisse
8- Biotita Granito Porfirítico

FIGURA 1 - (A) mapa de localização das áreas amostradas nos bairros de Maranduba e PerequêMirim - pontos A e B, respectivamente; (B) mapa geológico simplificado (CPRM 2015). 
Ao todo foram coletadas 19 amostras deformadas de solo para a realização de ensaios de caracterização física, 4 blocos indeformados (dimensões $30 \times 30 \times 30 \mathrm{~cm}$ ) e 16 corpos de prova em anéis cilíndricos biselados de PVC $(5,0 \mathrm{~cm}$ de altura e $4,0 \mathrm{~cm}$ de diâmetro interno) para a determinação das curvas de retenção de água. Algumas amostras deformadas e indeformadas também foram utilizadas em estudos mineralógicos e microestruturais.

A partir da utilização de critérios de inspeção tátil-visual de campo (e.g. presença de matéria orgânica, odor, cor, sensação ao tato, resistência do solo seco, dispersão em água, plasticidade e mobilidade da água intersticial) e seguindo as proposições sugeridas por DEERE \& PATTON (1971) e BLIGHT (2012), foi possível estabelecer divisões de classes para os horizontes de solos e propor um perfil de alteração típico para cada uma das áreas estudadas.

Para a obtenção dos pontos experimentais das CRA utilizou-se três métodos/técnicas empregados no Laboratório de Geotecnia da Escola Politécnica/USP: i) placa de sucção, ii) placa de pressão (translação de eixos) e iii) técnica do papel filtro. A placa de sucção foi utilizada para impor os seguintes incrementos de sucções: 1, $2,4,6,8,10,12,14,16,18,20,25$ e $30 \mathrm{kPa}$. Para o emprego da placa de pressão utilizou-se a técnica da translação de eixos proposta por HILF (1956), aplicando-se os seguintes níveis de sucções: $50,100,150,200,300$ e $400 \mathrm{kPa}$. O método do papel filtro (Whatman $\mathrm{n}^{\circ} 42$ ) foi utilizado para impor sucções superiores a $400 \mathrm{kPa}$. As equações de calibração em função da umidade para o papel filtro utilizado foram aquelas propostas inicialmente por CHANDLER et al. (1992). Os procedimentos de ensaios seguiram as especificações de MARINHO \& OLIVEIRA (2006). Maiores detalhes sobre os equipamentos utilizados podem ser consultados em MARINHO (1994) e MENDES (2008).

As CRA foram analisadas em função dos valores da sucção matricial e do teor de umidade volumétrica dos solos. Utilizou-se apenas um corpo de prova para a obtenção de todos os pontos experimentais da CRA representativa de cada tipo de solo. Os parâmetros de ajuste dos pontos experimentais das CRA dos solos foram obtidos com o software RETC-versão 6.0, desenvolvido no U.S. Salinity Laboratory, USDA, Riverside, CA.

A partir das amostras deformadas coletadas nas áreas de estudo também foram realizados os seguintes ensaios de caracterização física dos solos: análise granulométrica conjunta (NBR7181/84 e NBR-6502/95), determinação da massa específica dos grãos " $\rho_{\mathrm{s}}$ " (NBR-6508/84) e massa específica natural " $\rho$ " (NBR-10838). O estudo micromorfológico, que envolve aspectos mineralógicos e microestruturais, foi realizado em amostras indeformadas (lâminas delgadas de solo impregnados com resina acrílica) e amostras deformadas (pó de solo), fundamentando-se nos trabalhos de BREWER (1964), BOULET (1978), BOULET et al. (1982) e DELVIGNE (1998). O estudo micromorfológico integrou as análises de microscopia óptica de polarização e de difração de raios X, realizadas nos Laboratórios de Difração de Raios X e Microscopia Petrográfica do Instituto de Geociências da Universidade de São Paulo.

\section{RESULTADOS E DISCUSSÃO}

A partir das caracterizações física, mineralógica e microestrutural dos solos, detalhadas abaixo, e de acordo com o Mapa de Solos do Estado de São Paulo (OLIVEIRA et al. 1999), constatou-se que os dois perfis de solo estão inseridos na classe denominada Cambissolos Háplicos distróficos.

Os perfis de alteração típicos das áreas estudadas são caracterizados pelos seguintes horizontes: Horizonte I-A: solo superficial com raízes e matéria orgânica; Horizonte I-B (presente somente em Maranduba): zona tipicamente rica em argila, possibilidade de cimentação e ausência de estruturas reliquiares; Horizonte I-C: presença de estruturas reliquiares, graduação para materiais siltosos e arenosos, frequentemente micáceo, menos de 10\% de matacões; Horizonte II-A: desde materiais terrosos a rochosos, areia fina a grossa, 10 a 95\% de matacões; Horizonte II-B: material rochoso, rocha branda dura, descontinuidades presentes em diversos graus de alteração; Horizonte III: descontinuidades sem alteração e películas de óxidos de ferro, feldspatos e micas inalteradas. Nas figuras 2 e 3 são apresentados os perfis de alteração típicos de cada área investigada, bem como a indicação dos locais de coleta das amostras deformadas e indeformadas.

\subsection{Caracterização física dos solos}

De maneira geral, as amostras coletadas nos horizontes mais superficiais (M2A50, M2A30, P1A30 e Bloco 3) das áreas estudadas apresentaram um per- 

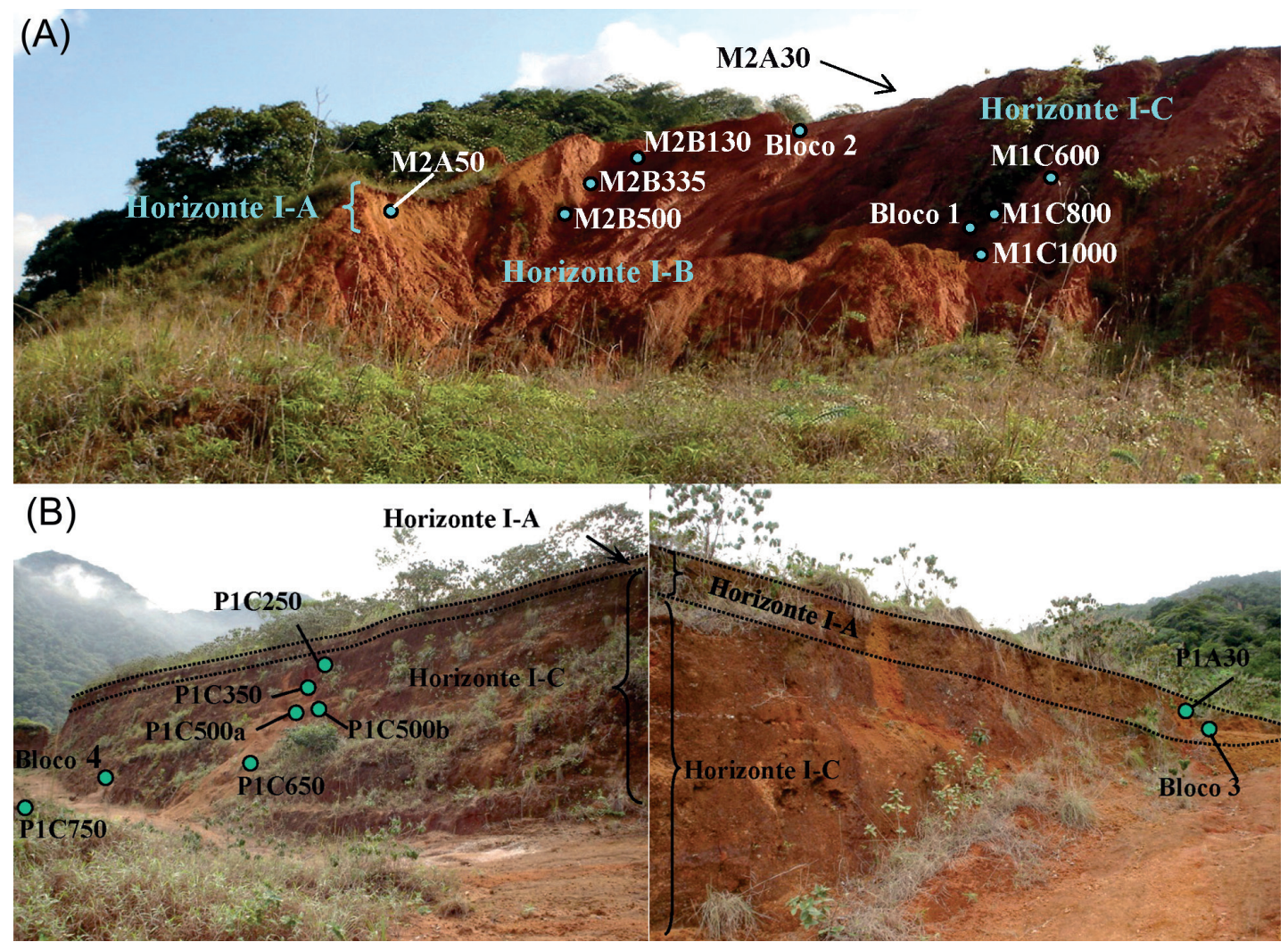

FIGURA 2 - Perfis de solo das áreas amostradas nos bairros de Maranduba e Perequê-Mirim - fotos A e B, respectivamente.

centual maior da fração argila, enquanto as amostras dos horizontes mais profundos (B e C) um percentual menor e maiores de areia e silte. Observa-se que os horizontes de solo de ambas as áreas tendem a apresentar uma diminuição na porcentagem de argila com o aumento da profundidade (Tabela 1).

\subsection{Caracterização mineralógica e microestrutural dos solos}

Essas análises tiveram como objetivo principal identificar e caracterizar os constituintes do solo e da rocha alterada, bem como aspectos texturais e microestruturais dos perfis de alteração, para posterior correlação com o comportamento de retenção de água.

As rochas de origem dos dois perfis de alteração são semelhantes do ponto de vista mineralógico, correspondendo a rochas graníticas (granitognaisse na área de Maranduba e charnockito na área do Perequê-Mirim), conforme observado nos difratogramas da figura 4. Esta condição contribui sobremaneira para a semelhança entre os dois perfis de alteração, que são basicamente compostos por oxi-hidróxidos de ferro e de alumínio, além de caulinita, argilomineral 1:1.
As tabelas 2 e 3 apresentam as composições mineralógicas dos perfis de alteração típicos das áreas de Maranduba e Perequê-Mirim, respectivamente. Os minerais listados nas tabelas incluem não apenas os detectados pelas análises de difração de raios $\mathrm{X}$, mas também aqueles observados nas lâminas delgadas ao microscópio óptico de luz refletida (Figuras 5 e 6 ).

Da base para o topo dos perfis de solo, os materiais encontram-se progressivamente mais intemperizados. A porosidade passa de praticamente nula (na rocha sã) a alta, depois diminui e volta a aumentar no solo stricto sensu, conforme apresentado nas figuras 5 e 6 . As porcentagens de argila aumentam em direção ao topo dos perfis de solo, mas de forma não linear. Analisando as tabelas 2 e 3 observa-se que os minerais supérgenos (minerais II) ocorrem desde a base dos perfis, sendo a gibbsita mais abundante que a caulinita, entre os minerais aluminosos. Já os produtos de alteração ferruginosos (hematita e magnetita), também abundantes, ocorrem disseminados ao longo dos perfis, preferencialmente nas zonas de maior circulação de água e também nas regiões onde ocorrem pseudomorfos micáceos. 


\section{Perfil de Alteração Típico (Maranduba)}

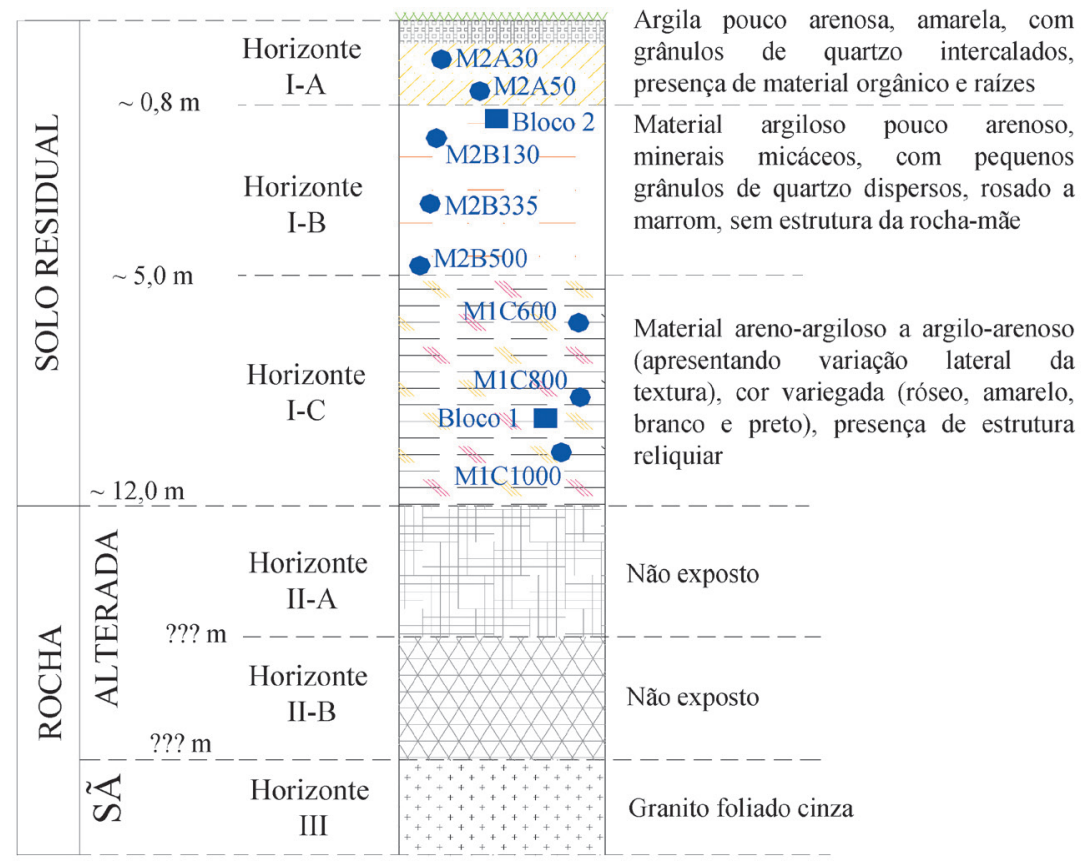

\section{Perfil de Alteração Típico (Perequê-Mirim)}

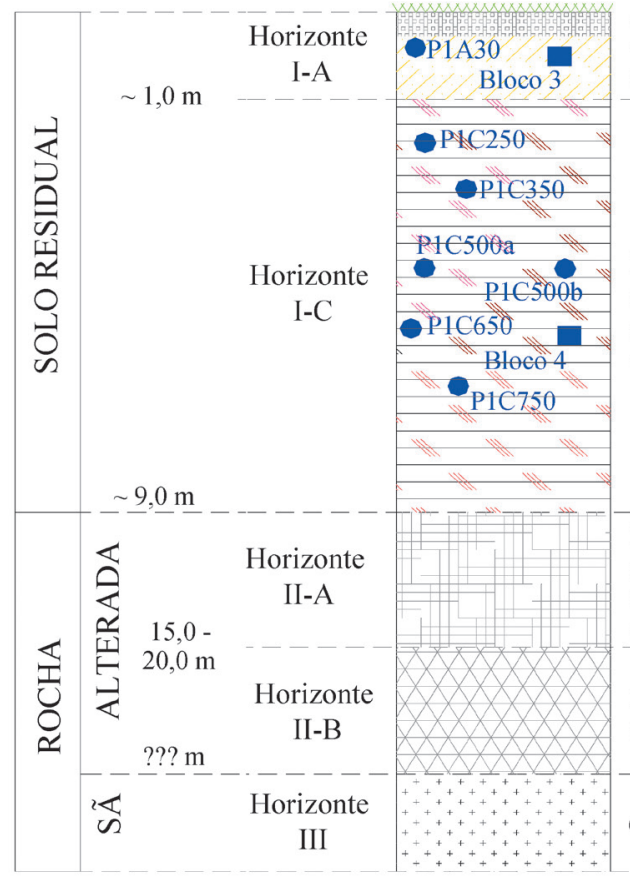

- Pontos de coleta das amostras indeformadas e deformadas
Argila arenosa, amarela e alaranjada, com muitos grânulos de quartzo, presença de material orgânico e raízes.

Material areno-siltoso, com grânulos de quartzo dispersos e estrutura reliquiar, rosado a marrom, apresentando variação vertical e lateral da textura.

Material muito heterogêneo, apresentando pouco material terroso e elevada quantidade de matacões com esfoliação esferoidal.

Material rochoso com descontinuidades em diversos graus de alteração.

Charnockito

Pontos de coleta dos "blocos de solo" indeformados

FIGURA 3 - Perfis de solo típicos das áreas estudadas e indicação dos pontos amostrados. 
TABELA 1 - Resultados dos ensaios de caracterização física dos solos estudados.

\begin{tabular}{|c|c|c|c|c|c|c|c|c|c|c|c|c|c|}
\hline \multirow{3}{*}{\multicolumn{2}{|c|}{ Amostra }} & \multirow{3}{*}{$H$} & \multirow{2}{*}{\multicolumn{2}{|c|}{$\begin{array}{c}\text { Localização } \\
\text { Geográfica }\end{array}$}} & \multirow{3}{*}{$\begin{array}{l}P r \\
\text { (m) }\end{array}$} & \multicolumn{6}{|c|}{ Granulometria (\%) } & \multirow{3}{*}{$\begin{array}{c}\rho \\
\left(\mathrm{g} / \mathrm{cm}^{3}\right)\end{array}$} & \multirow{3}{*}{$\begin{array}{c}\rho_{s} \\
\left(\mathrm{~g} / \mathrm{cm}^{3}\right)\end{array}$} \\
\hline & & & & & & \multirow{2}{*}{$P$} & \multicolumn{3}{|c|}{ Areia } & \multirow{2}{*}{ Silte } & \multirow{2}{*}{ Argila } & & \\
\hline & & & Longitude & Latitude & & & $G$ & $M$ & $F$ & & & & \\
\hline \multirow{10}{*}{ 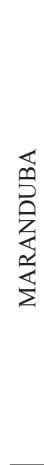 } & $\mathrm{M} 2 \mathrm{~A} 30$ & \multirow{2}{*}{ I-A } & $45^{\circ} 14^{\prime} 16,8^{\prime \prime}$ & $23^{\circ} 32^{\prime} 6,8^{\prime \prime}$ & 0,30 & 4,5 & 2,0 & 15,0 & 24,5 & 10,5 & 43,5 & 1,663 & 2,760 \\
\hline & M2A50 & & $45^{\circ} 14^{\prime} 7,9^{\prime \prime}$ & $23^{\circ} 32^{\prime} 9,4^{\prime \prime}$ & 0,50 & 0,0 & 1,0 & 13,0 & 21,0 & 8,5 & 56,5 & 1,628 & 2,761 \\
\hline & Bloco 2 & \multirow{4}{*}{ I-B } & $45^{\circ} 14^{\prime} 8,4^{\prime \prime}$ & $23^{\circ} 32^{\prime} 8,0^{\prime \prime}$ & 1,10 & 0,0 & 1,0 & 22,0 & 41,0 & 30,5 & 5,5 & 1,638 & 2,786 \\
\hline & M2B130 & & $45^{\circ} 14^{\prime} 8,2^{\prime \prime}$ & $23^{\circ} 32^{\prime} 8,8^{\prime \prime}$ & 1,30 & 0,0 & 1,0 & 18,0 & 25,5 & 37,0 & 18,5 & 1,455 & 2,816 \\
\hline & M2B335 & & $45^{\circ} 14^{\prime} 8,3^{\prime \prime}$ & $23^{\circ} 32^{\prime} 8,9^{\prime \prime}$ & 3,35 & 0,0 & 0,0 & 16,5 & 29,5 & 34,0 & 20,0 & 1,588 & 2,758 \\
\hline & M2B500 & & $45^{\circ} 14^{\prime} 8,2^{\prime \prime}$ & $23^{\circ} 32^{\prime} 9,0^{\prime \prime}$ & 5,00 & 0,0 & 1,0 & 11,5 & 48,5 & 35,5 & 3,5 & 1,448 & 2,749 \\
\hline & M1C600 & \multirow{4}{*}{$\mathrm{I}-\mathrm{C}$} & $45^{\circ} 14^{\prime} 7,8^{\prime \prime}$ & $23^{\circ} 32^{\prime} 9,5^{\prime \prime}$ & 6,00 & 0,0 & 2,0 & 33,0 & 34,5 & 28,0 & 2,5 & 1,818 & 2,751 \\
\hline & M1C800 & & $45^{\circ} 14^{\prime} 7,7^{\prime \prime}$ & $23^{\circ} 32^{\prime} 9,5^{\prime \prime}$ & 8,00 & 0,0 & 4,5 & 20,5 & 32,5 & 38,5 & 4,0 & 1,607 & 2,762 \\
\hline & Bloco 1 & & $45^{\circ} 14^{\prime} 7,6^{\prime \prime}$ & $23^{\circ} 32^{\prime} 9,4^{\prime \prime}$ & 9,00 & 0,0 & 2,0 & 15,5 & 30,5 & 46,0 & 6,0 & 1,578 & 2,825 \\
\hline & M1C1000 & & $45^{\circ} 14^{\prime} 7,6^{\prime \prime}$ & $23^{\circ} 32^{\prime} 9,3^{\prime \prime}$ & 10,00 & 0,0 & 0,0 & 3,0 & 22,0 & 53,5 & 21,5 & 1,502 & 3,219 \\
\hline \multirow{9}{*}{ 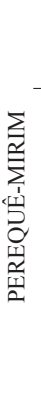 } & $\mathrm{P} 1 \mathrm{~A} 30$ & \multirow{2}{*}{ I-A } & $45^{\circ} 06^{\prime} 43,7^{\prime \prime}$ & $23^{\circ} 28^{\prime} 53,0^{\prime \prime}$ & 0,30 & 1,0 & 8,5 & 22,5 & 23,0 & 16,5 & 28,5 & 1,582 & 2,659 \\
\hline & Bloco 3 & & $45^{\circ} 06^{\prime} 43,7^{\prime \prime}$ & $23^{\circ} 28^{\prime} 53,0^{\prime \prime}$ & 0,50 & 0,0 & 4,0 & 24,5 & 25,0 & 15,5 & 31,0 & 1,739 & 2,713 \\
\hline & $\mathrm{P} 1 \mathrm{C} 250$ & \multirow{7}{*}{ I-C } & $45^{\circ} 06^{\prime} 42,6^{\prime \prime}$ & $23^{\circ} 28^{\prime} 52,1^{\prime \prime}$ & 2,50 & 1,0 & 5,5 & 22,0 & 29,0 & 20,5 & 22,0 & 1,225 & 2,753 \\
\hline & P1C350 & & $45^{\circ} 06^{\prime} 42,7^{\prime \prime}$ & $23^{\circ} 28^{\prime} 52,1^{\prime \prime}$ & 3,50 & 5,0 & 14,0 & 26,5 & 18,5 & 21,0 & 15,0 & 1,235 & 2,744 \\
\hline & P1C500a & & $45^{\circ} 06^{\prime} 42,6^{\prime \prime}$ & $23^{\circ} 28^{\prime} 52,1^{\prime \prime}$ & 5,00 & 9,2 & 12,4 & 27,6 & 21,8 & 24,0 & 5,0 & 1,419 & 2,775 \\
\hline & $\mathrm{P} 1 \mathrm{C} 500 \mathrm{~b}$ & & $45^{\circ} 06^{\prime} 42,6^{\prime \prime}$ & $23^{\circ} 28^{\prime} 52,0^{\prime \prime}$ & 5,00 & 0,0 & 5,0 & 27,0 & 23,0 & 26,5 & 18,5 & 1,827 & 2,764 \\
\hline & P1C650 & & $45^{\circ} 06^{\prime} 42,7^{\prime \prime}$ & $23^{\circ} 28^{\prime} 51,7^{\prime \prime}$ & 6,50 & 1,0 & 4,8 & 19,2 & 27,5 & 33,3 & 14,2 & 1,468 & 2,737 \\
\hline & Bloco 4 & & $45^{\circ} 06^{\prime} 42,2^{\prime \prime}$ & $23^{\circ} 28^{\prime} 51,8^{\prime \prime}$ & 6,70 & 0,0 & 5,0 & 18,5 & 26,5 & 40,0 & 10,0 & 1,532 & 2,766 \\
\hline & $\mathrm{P} 1 \mathrm{C} 750$ & & $45^{\circ} 06^{\prime} 42,7^{\prime \prime}$ & $23^{\circ} 28^{\prime} 51,9^{\prime \prime}$ & 7,50 & 9,0 & 17,5 & 27,5 & 25,0 & 18,5 & 2,5 & 1,577 & 2,646 \\
\hline
\end{tabular}

Legenda: $\mathrm{H}$ - horizonte; $\mathrm{Pr}$ - profundidade de coleta das amostras; $\mathrm{P}$ - pedregulho; $\mathrm{G}$ - areia grossa; $\mathrm{M}$ - areia média; $\mathrm{F}$ - areia fina; $\rho$ - massa específica natural do solo; $\rho_{\mathrm{S}}$ - massa específica dos grãos de solo; segundo normas NBR-6508 (ABNT 1984a), NBR-7181 (ABNT 1984b), NBR-10838 (ABNT 1984c) e NBR-6502 (ABNT 1995).

TABELA 2 - Caracterização mineralógica das amostras de solo de Maranduba a partir de difratometria de raios $\mathrm{X}$ e microscopia óptica de luz refletida.

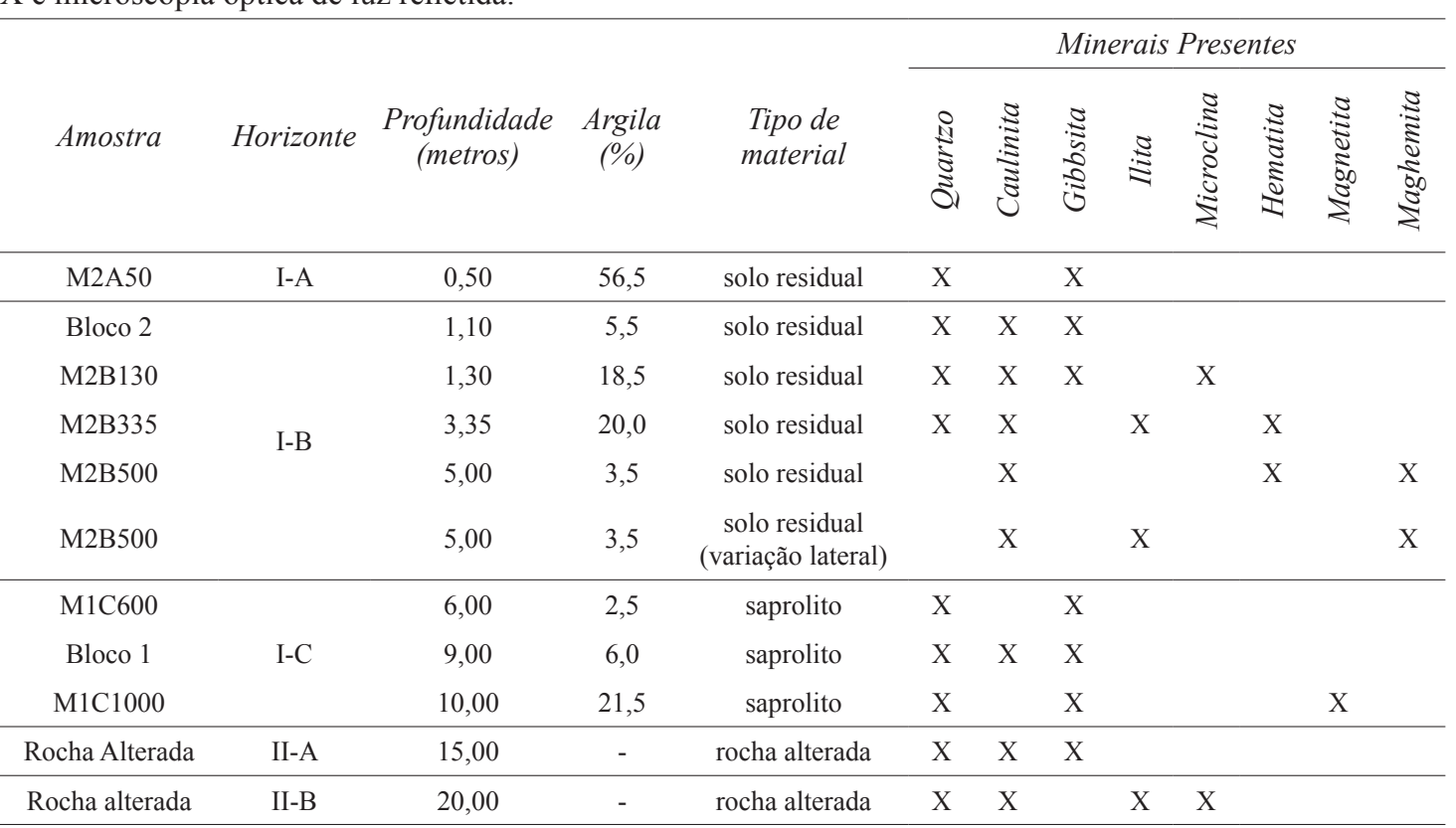


TABELA 3 - Caracterização mineralógica das amostras de solo de Perequê-Mirim a partir de difratometria de raios $\mathrm{X}$ e microscopia óptica de luz refletida.

\begin{tabular}{|c|c|c|c|c|c|c|c|c|c|}
\hline \multirow[b]{2}{*}{ Amostra } & \multirow[b]{2}{*}{ Horizonte } & \multirow[b]{2}{*}{$\begin{array}{l}\text { Profundidade } \\
\text { (metros) }\end{array}$} & \multirow[b]{2}{*}{$\begin{array}{c}\text { Argila } \\
(\%)\end{array}$} & \multirow[b]{2}{*}{ Tipo de material } & \multicolumn{5}{|c|}{ Minerais Presentes } \\
\hline & & & & & ה & 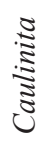 & 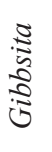 & $\stackrel{\Xi}{\Sigma}$ & 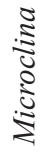 \\
\hline Bloco 3 & $\mathrm{I}-\mathrm{A}$ & 0,50 & 31,0 & solo residual & $\mathrm{X}$ & $\mathrm{X}$ & $\mathrm{X}$ & & \\
\hline $\mathrm{P} 1 \mathrm{C} 350$ & & 3,50 & 15,0 & saprolito & $\mathrm{X}$ & $\mathrm{X}$ & $\mathrm{X}$ & & \\
\hline $\mathrm{P} 1 \mathrm{C} 350$ & $\mathrm{I}-\mathrm{C}$ & 3,50 & 15,0 & $\begin{array}{c}\text { Saprolito } \\
\text { (variação lateral) }\end{array}$ & $\mathrm{X}$ & $\mathrm{X}$ & $X$ & & \\
\hline Bloco 4 & & 6,70 & 10,0 & saprolito & $\mathrm{X}$ & $\mathrm{X}$ & & $\mathrm{X}$ & $\mathrm{X}$ \\
\hline $\mathrm{P} 1 \mathrm{C} 750$ & & 7,50 & 2,5 & saprolito & $\mathrm{X}$ & $\mathrm{X}$ & & $\mathrm{X}$ & $\mathrm{X}$ \\
\hline $\begin{array}{l}\text { Rocha } \\
\text { Alterada }\end{array}$ & II-A & 11,00 & - & rocha alterada & $\mathrm{X}$ & $\mathrm{X}$ & & & $\mathrm{X}$ \\
\hline $\begin{array}{l}\text { Rocha } \\
\text { Alterada }\end{array}$ & II-B & 15,00 & - & rocha alterada & $X$ & $X$ & $\mathrm{X}$ & $\mathrm{X}$ & $\mathrm{X}$ \\
\hline
\end{tabular}
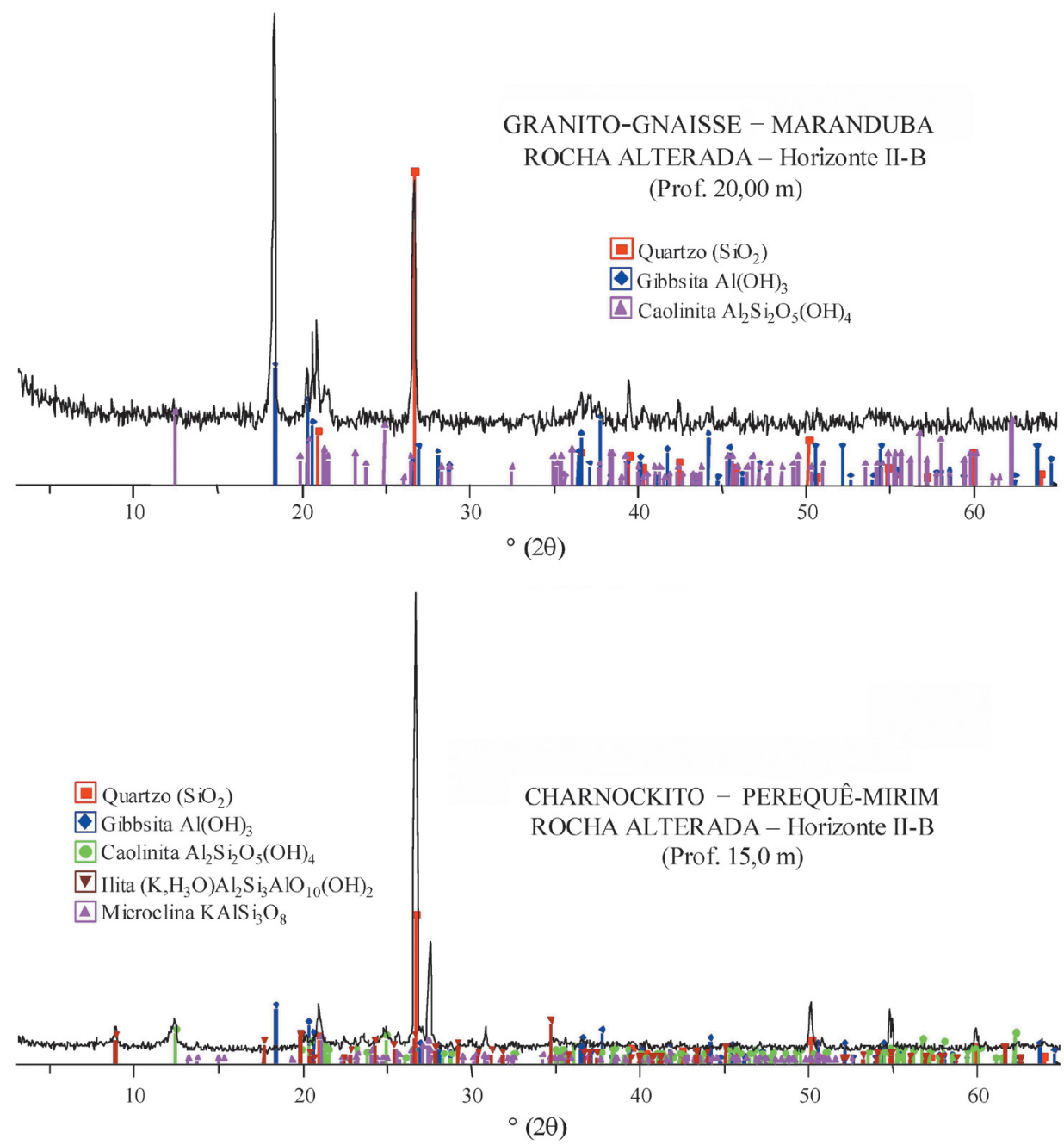

FIGURA 4 - Difratogramas característicos das rochas alteradas de granito-gnaisse e charnockito. 
Horizonte I-A (Amostra M2A50)

Presença de fissuras separando volumes de fundo matricial e insta lação da estrutura aglomeroplásmica. Predomínio de plasma II (argilo-ferruginoso) e quase não há pseudomorfos micáceos. Há alguns pequenos agregados de gibbsita na forma de nódulos ou altero-relíquias). Material poroso.

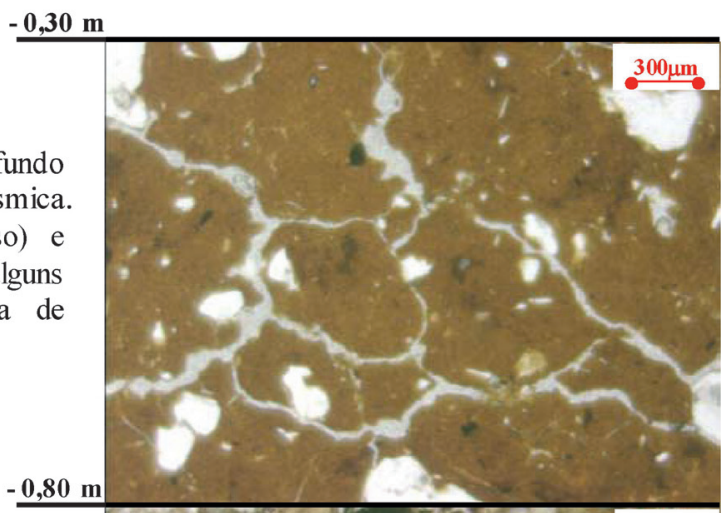

\section{Horizonte I-B (Amostra Bloco 2)}

Aloterita. Plasma II muito ferruginoso com abundância de fragmentos de quartzo e magnetita e pseudomorfos de mica; proporção de grãos do esqueleto, plasma I e plasma II praticamente equilibrada. Material poroso.

\section{Horizonte I-C (Amostra B loco 1)}

Aloterita em estágio de transição. Plasma II caolinítico (talvez também gibbsítico) porfirosquélico, com abundância de fragmentos de quartzo e magnetita parcialmente dissolvida, pseudomorfos micáceos caolinizados e pouco ferruginizados, com manchas e faixas vermelhas de oxi-hidróxidos de ferro. Porosidade variável em função do caráter de transição isalterita/aloterita.

\section{Horizo nte II-A (Rocha Alterada)}

Granito intemperizado com estrutura conservada (isalterita), com as seguintes filiações mineralógicas observadas: feldspato resultando em gibbsita, hornblenda e biotita em oxi-hidróxidos de ferro e gibbsita; quartzo parcialmente dissolvido. Apresenta macroporosidade nos vazios dos pseudomorfos e em fissuras transminerais; a microporosidade é inferida pela textura nos volumes formados pelos minerais supérgenos em textura mais maciça.

$-12,00 \mathrm{~m}$
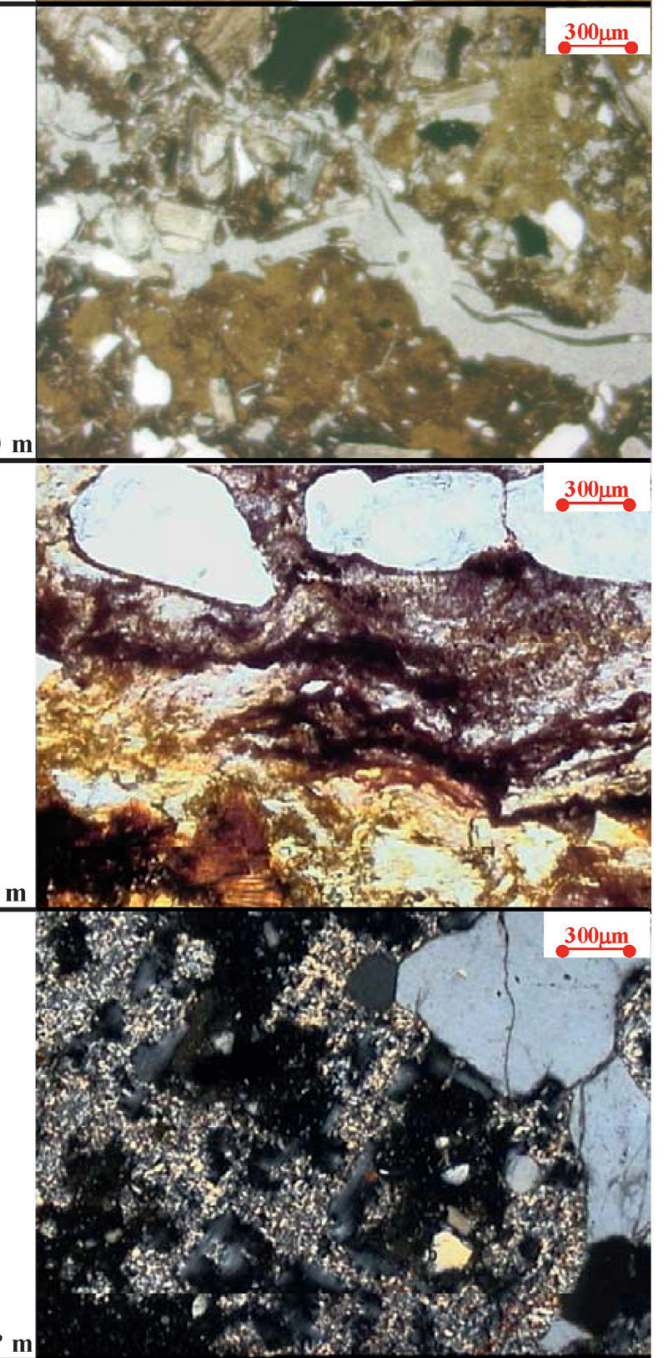

??? m

FIGURA 5 - Feições micromorfológicas observadas nas lâminas delgadas dos horizontes de solo representativos do perfil de alteração de Maranduba. 


\section{Horizonte I-A (Amostra B loco 3)}

Material com estrutura porfirosquélica tendendo a aglomeroplásmica. Apresenta fragmentos de quartzo, magnetita e de agregados de gibbsita. Material muitíssimo poroso com macroporosidade visível.

\section{Horizonte I-C (Amostra P1C350)}

Aloterita. Plasma II argilo-ferruginoso com grande quantidade de fragmentos de quartzo de tamanhos variados, fragmentos de magnetita e pseudomorfos micáceos; pequenos agregados de gibbsita. Material com significativa porosidade, mas menor que o horizonte superior.

\section{Ho rizonte I-C (Amostra Bloco 4)}

Isalterita. Plasma II de caulinita com esqueleto (quartzo+magnetita) e Plasma I de pseudomorfos micáceos totalmente caulinizados ou não, mais ou menos ferruginizados (em abundância). Os grãos de quartzo estão muito fragmentados e com sinais de dissolução. Material com elevada quantidade de micro e macroporos.

\section{Horizonte III (Rocha Sã)}

Charnockito de granulometria grosseira, com volumes restritos mais finos. Início da alteração de piroxênio, com formação de produtos ferruginosos nas descontinuidades e início de formação de

porosidade.

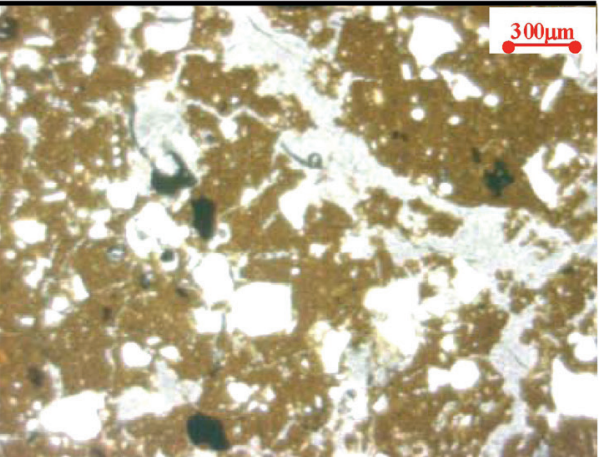

\section{$-5,00 \mathrm{~m}$}
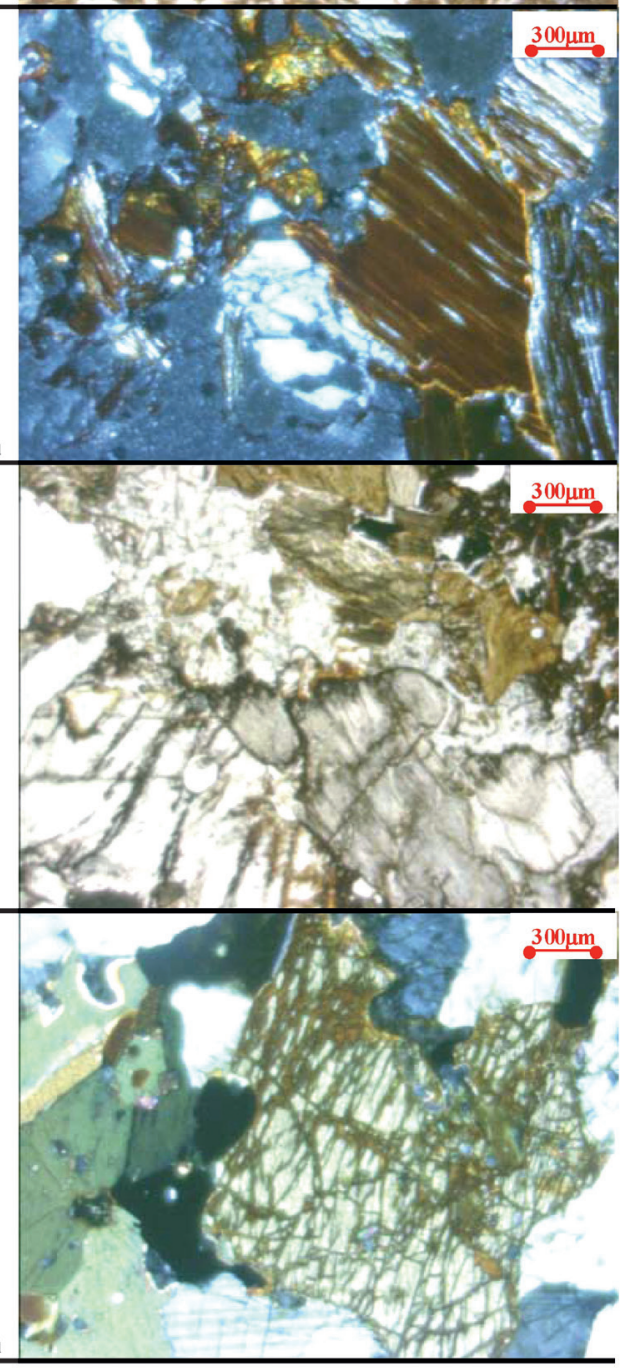

FIGURA 6 - Feições micromorfológicas observadas nas lâminas delgadas dos horizontes de solo representativos do perfil de alteração de Perequê-Mirim. 


\subsection{Curvas de retenção de água dos solos (CRA)}

Os parâmetros dos modelos matemáticos que melhor se ajustaram aos pontos experimentais são apresentados na tabela 4. Observa-se que a maior parte das CRA experimentais foi ajustada pelo modelo "dual porosity" de DURNER (1994), enquanto as demais, pelo modelo de VAN GENUCHTEN (1980).

Nas figuras 7 e 8 são apresentadas as curvas ajustadas, conforme os modelos matemáticos utilizados, para os pontos experimentais que compõem as CRA de todos os solos analisados. Observa-se que os modelos ajustaram-se bem aos pontos experimentais para todas as CRA dos solos estudados. Nota-se que as CRA dos solos do horizonte superficial (e.g. amostras P1A30, Bloco3, Bloco1, M2A30), apresentam um "patamar" mais evidente em relação aos solos dos demais horizontes (e.g. amostras M2B335, M2B130, P1C250, P1C650), onde uma pequena variação do teor de umidade volumétrico gera uma grande variação de sucção. A maior parte das CRA das amostras, ajustadas pelo modelo de Durner, sugere existir um comportamento de distribuição dos tamanhos de poros do tipo bimodal.
Para os solos do horizonte superficial (I-A) dos dois perfis de alteração, verifica-se comportamentos de retenção de água muito semelhantes. Para o horizonte intermediário (I-B), presente apenas no perfil de solo de Maranduba, observa-se que nem todas as curvas apresentam o "patamar" de forma pronunciada. Além disso, pode-se constatar que os solos desse horizonte possuem comportamento semelhante de retenção de água, ou seja, apresentam valores de sucção muito próximos para cada valor de umidade, com exceção da amostra M2B335 (horizonte I-B), que tende a reter mais água para um dado nível de sucção. Esse comportamento provavelmente deve estar relacionado com a quantidade de argila presente em seu arcabouço, que é de $20 \%$ (Tabela 1), portanto, maior do que as demais amostras de solo do mesmo horizonte.

A amostra M1C800 (horizonte I-C) apresenta uma maior capacidade de retenção de água que os demais solos, principalmente para valores de sucção entre 10 a $300 \mathrm{kPa}$. Acredita-se que esse comportamento deva ser influenciado principalmente por sua microestrutura caracterizada pela maior quan-

TABELA 4 - Parâmetros dos modelos matemáticos de ajuste das CRA dos solos estudados.

\begin{tabular}{cccccccccccccc}
\hline \multirow{2}{*}{ Amostra } & \multirow{2}{*}{$\mathrm{H}$} & $\begin{array}{c}\text { Modelo de } \\
\text { Ajuste }\end{array}$ & $\begin{array}{c}\theta_{R} \\
(\%)\end{array}$ & $\begin{array}{c}\theta_{S} \\
(\%)\end{array}$ & $\begin{array}{c}\alpha_{1} \\
(1 / \mathrm{cm})\end{array}$ & $n_{1}$ & $m_{1}$ & $w_{1}$ & $\begin{array}{c}\alpha_{2} \\
(1 / \mathrm{cm})\end{array}$ & $n_{2}$ & $m_{2}$ & $w_{2}$ & $R^{2}$ \\
\hline M2A30 & \multirow{2}{*}{ I-A } & Durner & 0,0 & 60,6 & 0,002 & 2,694 & 0,628 & 0,5 & 1041,745 & 1,152 & 0,132 & 0,5 & 0,99 \\
M2A50 & & Durner & 0,0 & 54,9 & 0,002 & 3,744 & 0,733 & 0,5 & 155,719 & 1,079 & 0,073 & 0,5 & 0,99 \\
\hline Bloco 2 & & Durner & 0,0 & 45,8 & 0,008 & 2,162 & 0,537 & 0,5 & 2,573 & 1,225 & 0,183 & 0,5 & 0,99 \\
M2B130 & \multirow{2}{*}{ I-B } & Durner & 0,0 & 47,0 & 3,416 & 1,165 & 0,141 & 0,5 & 0,007 & 2,511 & 0,602 & 0,5 & 0,99 \\
M2B335 & & Durner & 0,0 & 54,2 & 0,007 & 1,850 & 0,459 & 0,5 & 10,350 & 1,080 & 0,074 & 0,5 & 0,99 \\
M2B500 & & Durner & 0,0 & 52,3 & 6,837 & 1,269 & 0,212 & 0,5 & 0,007 & 2,130 & 0,531 & 0,5 & 0,99 \\
\hline M1C600 & & Durner & 0,0 & 51,3 & 0,015 & 1,806 & 0,446 & 0,5 & 3,264 & 1,224 & 0,183 & 0,5 & 0,99 \\
M1C800 & \multirow{2}{*}{ I-C } & Van Genuchten & 0,0 & 62,7 & 0,017 & 1,543 & 0,352 & 1,0 & - & - & - & - & 0,98 \\
Bloco 1 & & Durner & 0,0 & 52,1 & 0,008 & 2,834 & 0,647 & 0,5 & 3,436 & 1,361 & 0,265 & 0,5 & 0,99 \\
M1C1000 & & Van Genuchten & 0,0 & 57,6 & 0,021 & 1,772 & 0,375 & 1,0 & - & - & - & - & 0,99 \\
\hline P1A30 & \multirow{2}{*}{ I-A } & Durner & 0,0 & 44,3 & 0,002 & 2,485 & 0,597 & 0,5 & 10,323 & 1,389 & 0,280 & 0,5 & 0,99 \\
Bloco 3 & & Durner & 0,0 & 42,0 & 0,002 & 2,915 & 0,657 & 0,5 & 28,356 & 1,161 & 0,139 & 0,5 & 0,99 \\
\hline P1C250 & & Durner & 0,2 & 51,9 & 0,003 & 2,699 & 0,629 & 0,5 & 2,420 & 1,350 & 0,259 & 0,5 & 0,98 \\
P1C350 & & Durner & 0,0 & 40,0 & 0,004 & 2,460 & 0,593 & 0,5 & 1,978 & 1,136 & 0,120 & 0,5 & 0,99 \\
P1C500a & & Van Genuchten & 0,0 & 39,9 & 20,351 & 1,203 & 0,168 & 1,0 & - & - & - & - & 0,98 \\
\hline P1C500b & I-C & Van Genuchten & 0,0 & 39,4 & 7,193 & 1,243 & 0,195 & 1,0 & - & - & - & - & 0,96 \\
P1C650 & & Durner & 0,0 & 40,3 & 0,009 & 2,705 & 0,630 & 0,5 & 4,067 & 1,098 & 0,089 & 0,5 & 0,99 \\
Bloco 4 & & Durner & 0,0 & 52,7 & 0,015 & 1,805 & 0,446 & 0,5 & 5,852 & 1,271 & 0,214 & 0,5 & 0,99 \\
P1C750 & & Van Genuchten & 0,0 & 42,2 & 33,749 & 2,210 & 0,095 & 1,0 & - & - & - & - & 0,96 \\
\hline
\end{tabular}

Legenda: $\mathrm{H}$ - horizonte; $\theta_{R}$ - teor de umidade volumétrica residual; $\theta_{S}$ - teor de umidade volumétrica saturado; $\alpha, n, m, w$ - parâmetros de ajuste das equações de Durner e Van Genuchten; $\mathrm{R}^{2}$ - coeficiente de correlação. 
tidade de microporos, uma vez que a porcentagem de argila dessa amostra é muito baixa - 4\% (Tabela 1 ).

A maioria das CRA do horizonte mais profundo (I-C) de ambas as áreas estudadas foi ajustada pelo modelo de Van Genuchten e tende a não apresentar "patamares", ou seja, sugere existir uma distribuição de poros do tipo monomodal (microporos). Os solos do horizonte I-C também tendem a apresentar maior
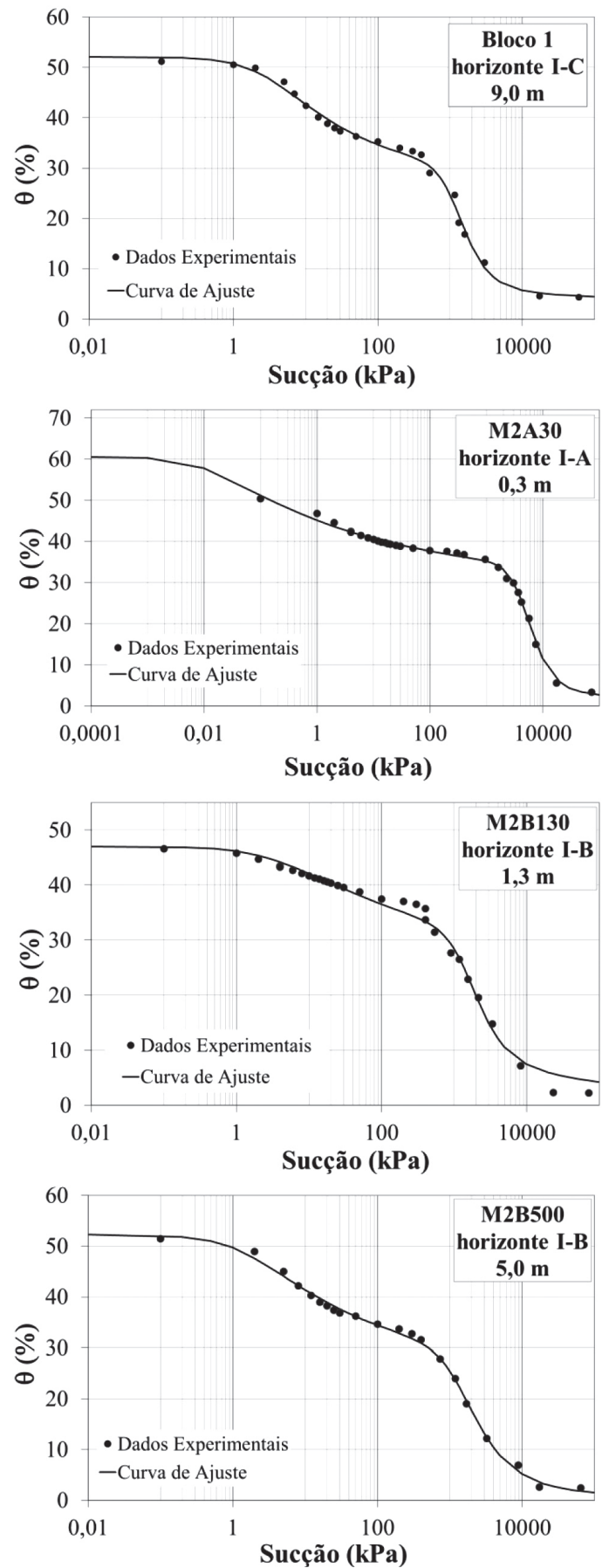

capacidade de retenção de água em comparação com os demais tipos de solo dos horizontes I-A e I-B.

Verifica-se, portanto, que este comportamento nem sempre está relacionado com o conteúdo e tipo de argilomineral presente no arcabouço do solo, mas tende a estar principalmente associado aos aspectos microestruturais do solo, por meio da quantidade e distribuição de macro e microporos.
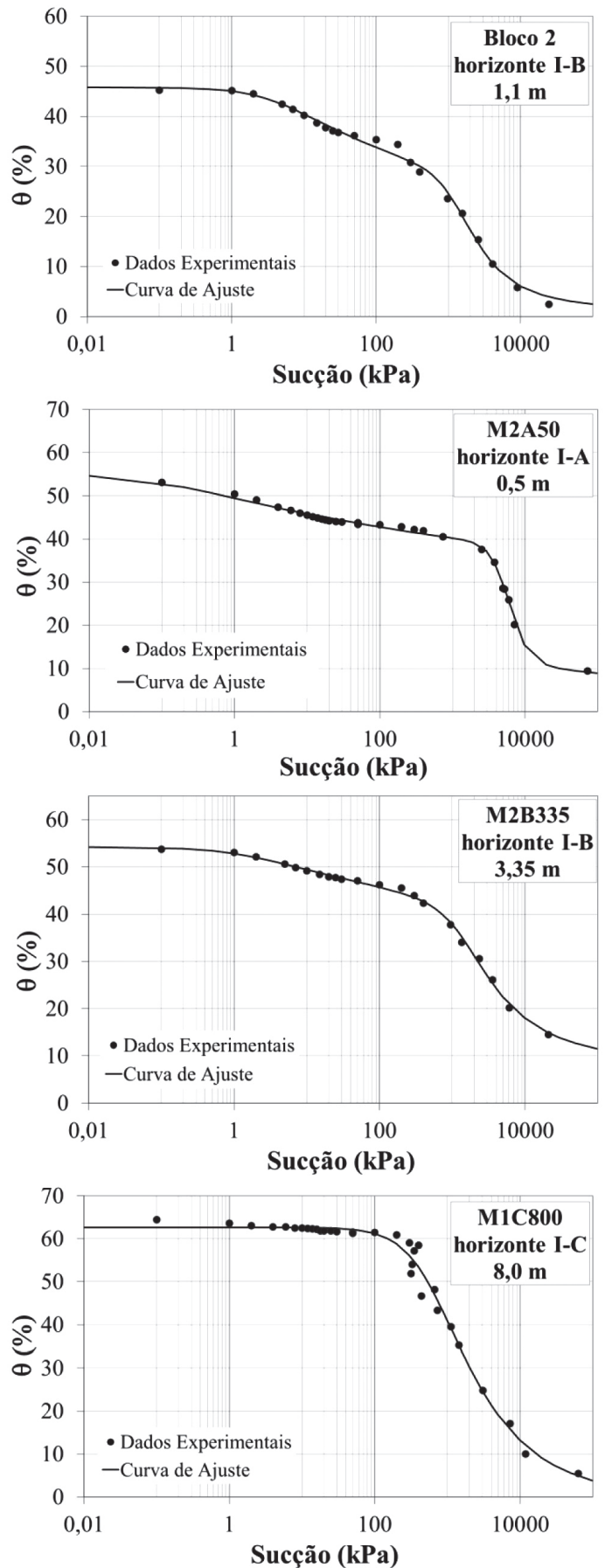

FIGURA 7 - Dados experimentais e curvas de ajuste dos solos representativos do perfil de alteração de Maranduba. 

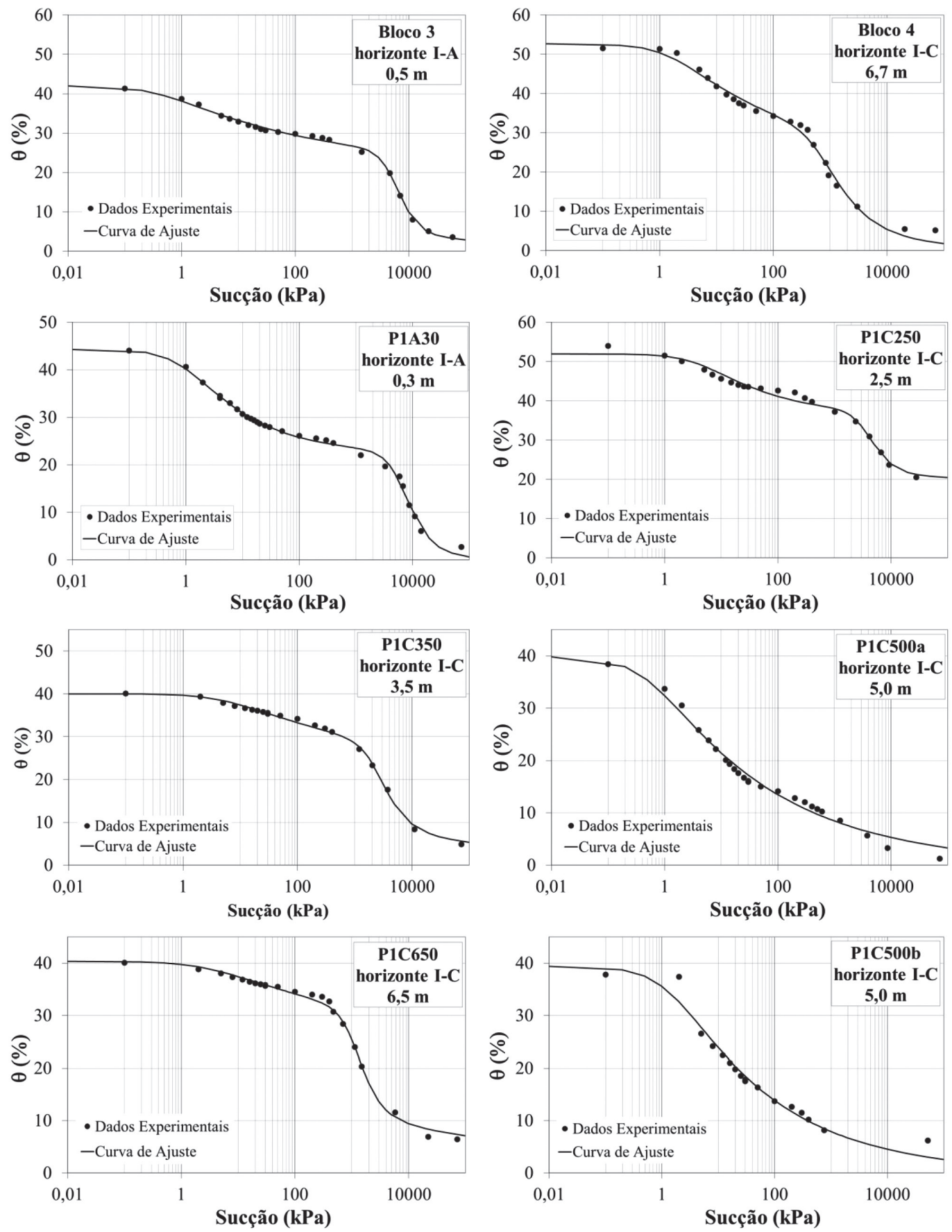

FIGURA 8 - Dados experimentais e curvas de ajuste dos solos representativos do perfil de alteração de Perequê-Mirim.

\section{CONCLUSÕES}

As curvas de retenção de água apresentaram diferentes tipos de comportamento ao longo dos perfis de solo estudados. Essas diferenças devem estar relacionadas com o grau de intemperismo aos quais as rochas estiveram submetidas, pois as análises texturais e microestruturais revelaram existir uma tendência de diminuição da porcentagem de argila e aumento da quantidade de microporos, à medida que se aumenta a profundidade dos perfis de solo. No perfil de solo de Maranduba o horizonte I-A é caracterizado por uma significativa quantidade de argila e de macroporos e, à medida que se avança em direção ao horizonte I-B, ocorre uma diminuição da fração argilosa e 
aumento da quantidade de microporos, até que no horizonte I-C a porcentagem de argila passa a ser igual ou ligeiramente inferior e a quantidade de microporos no arcabouço do solo é praticamente dominante. Observou-se que no perfil de solo de Perequê-Mirim, o comportamento é semelhante, porém com algumas diferenças entre as proporções de macro e microporos e da quantidade de argila. Um fato que merece ser destacado é que o comportamento de retenção de água nem sempre está relacionado exclusivamente com as características mineralógicas e texturais do solo, mas associa-se também com os aspectos microestruturais do solo, por meio da distribuição de macro e microporos no arcabouço do solo.

Ressalta-se o formato bimodal das curvas de retenção de água obtidas para a maioria dos solos estudados (modelo Durner), apresentando trechos com "patamares", onde se verificou que uma pequena variação do teor de umidade gera uma grande variação de sucção. Dependendo das variações da umidade do solo observadas no campo e do tipo de curva de retenção de água, estes trechos poderão influenciar positiva ou negativamente o comportamento de condutividade hidráulica. Por exemplo, aplicando-se as curvas de retenção de água obtidas no presente trabalho numa análise de estabilidade de encosta acoplada com análises de fluxo transiente, espera-se que o perfil de alteração de Maranduba seja mais suscetível à ocorrência de escorregamentos, pois esse perfil apresenta horizontes superficiais de solo (horizontes I-A e I-B) com maior capacidade de retenção de água durante eventos chuvosos.

\section{AGRADECIMENTOS}

Os autores agradecem à FAPESP (Processo $\mathrm{n}^{\circ}$ 05/55736-5) pela disponibilização dos recursos para o desenvolvimento do projeto de doutorado do primeiro autor e ao CNPq pela bolsa de produtividade em pesquisa do segundo autor.

\section{REFERÊNCIAS BIBLIOGRÁFICAS}

ABNT - ASSOCIAÇÃO BRASILEIRA DE NORMAS TÉCNICAS. 1984a. Grãos de solo que passam na peneira de $4,8 \mathrm{~mm}-$ Determinação da massa específica - NBR6508. Rio de Janeiro, 8 p.

ABNT - ASSOCIAÇÃO BRASILEIRA DE NORMAS TÉCNICAS. 1984b. Solo - Análise granulométrica - NBR-7181. Rio de Janeiro, 13 p.
ABNT - ASSOCIAÇÃO BRASILEIRA DE NORMAS TÉCNICAS. 1984c. Solo - Determinação da massa específica aparente de amostras indeformadas, com emprego da balança hidrostática, NBR 10838. Rio de Janeiro, 6 p.

ABNT - ASSOCIAÇÃO BRASILEIRA DE NORMAS TÉCNICAS. 1995. Rochas e solos NBR-6502. Rio de Janeiro, 12 p.

BLIGHT, G.E. 2012. Origin and formation of residual soils. In: G.E. Blight \& E.C. Leong (ed.) Mechanics of Residual Soils, Leiden, Balkema, p. 1-40.

BOULET, R. 1978. Toposéquences des sols tropicaux en Haute-Volta: equilibre et déséquilibre pedobioclimatique. Université Stasbourg et Orstom, Paris, Thèse de Doctorat, $272 \mathrm{p}$.

BOULET, R; CHAUVEL, A.; HUMBEL F.X.; LUCAS, Y. 1982. Analyse structurale et cartographie en pédologie (I) - les études de toposéquences et principaux apports à la connaissance des sols. Cahiers ORSTOM, 19(4): 309-321.

BREWER, R. 1964. Fabric and mineral analysis of soils. John Wiley \& Sons, New York, 482 p.

CHANDLER, R.J.; CRILLY, M.S.; MONTGOMERYSMITH, G. 1992. A low-cost method of assessing clay desiccation for low-rise buildings. In: Institution of Civil Engineers (Civil Engineering), Proceedings, 92(2): 82-89.

COOPER, M.; MEDEIROS, J.C.; ROSA, J.D.; SORIA, J.E.; TOMA, R.S. 2013. Soil functioning in a toposequence under rainforest in São Paulo, Brazil. Revista Brasileira de Ciência do Solo, 37: 392-399.

CPRM - COMPANHIA DE PESQUISA DE RECURSOS MINERAIS. 2015. Cartografia geológica regional: geologia e recursos minerais do Estado de São Paulo - escala 1:750.000. Disponível em http://www.cprm.gov.br/publique/cgi/ cgilua.exe/sys/start.htm? infoid $=624 \&$ sid $=9$. Acessado em 11 set. 2015.

DEERE, D.V.; PATTON, F.D. 1971. Slope stability in residual soils. In: Pan American Conference on Soil Mechanics and Foundation, 4, Puerto Rico, Proceedings, 1: 87-170. 
DELVIGNE, J.E. 1998. Atlas of micromorphology of mineral alteration and weathering. Mineralogical Association of Canada, Ontario, $494 \mathrm{p}$.

DURNER, W. 1994. Hydraulic conductivity estimation for soils with heterogeneous pore structure. Water Resources Research, 30(2): 211-223.

EMBRAPA - EMPRESA BRASILEIRA DE PESQUISA AGROPECUÁRIA. 2013. Sistema Brasileiro de Classificação de Solos. Embrapa, Brasília, 353 p.

FREDLUND, D. G.; RAHARDJO, H. 1993. Soil mechanics for unsaturated soils. John Wiley \& Sons, New York, 544 p.

FREDLUND, D.G.; XING, A. 1994. Equations for the soil water characteristics curve. Canadian Geotechnical Journal, 31(4): 521-532.

HILF, J.W. 1956. An investigation of pore pressure in cohesive soils. U.S. Dep. Of the Interior, Bureau of Reclamation, Design and Construction Div., Denver, Doctoral Thesis, 654 p.

MARINHO, F.A.M. 1994. Medição de sucção com o método do papel filtro. In: ABMS, COBRAMSEF, 10, Foz do Iguaçu, Anais, 1: 515-522.

MARINHO, F.A.M.; OLIVEIRA, O.M. 2006. The filter paper method revisited. Geotechnical Test Journal, 29(3): 250-258.
MARQUES, J.D.; LIBARDI, P.L.; VAN LIER, Q.J. 2002. Relação entre horizontes pedológicos e propriedades hidráulicas em dois latossolos. Revista Brasileira de Ciência do Solo, 26: 567-577.

MENDES, R.M. 2008. Estudo das propriedades geotécnicas de solos residuais não saturados de Ubatuba (SP). Escola Politécnica, USP, São Paulo, Tese de Doutorado, 254 p.

MORAES, S.O.; LIBARDI, P.L.; NETO, D.D. 1993. Problemas metodológicos na obtenção da curva de retenção da água pelo solo. Scientia Agricola, 50(3): 383-392.

OLIVEIRA, J.B.; CAMARGO, M.N.; ROSSI, M.; CALDERANO FILHO, B. 1999. Mapa pedológico do Estado de São Paulo: legenda expandida. IAC/Embrapa Solos, Campinas, $64 \mathrm{p}$.

OTTO, S.R.L.; ALCAIDE, M. 2001. Utilização do método TDR - tensiômetro na obtenção da curva de retenção de água no solo. Revista Brasileira de Engenharia Agricola e Ambiental, 5(2): 265-269.

VAN GENUCHTEN, M. Th. 1980. A closedform equation for predicting the hydraulic conductivity of unsaturated soils. Soil Science Society of America Journal, 44: 892-898.

Endereço dos autores:

Rodolfo Moreda Mendes - Centro Nacional de Monitoramento e Alertas de Desastres Naturais CEMADEN, Estrada Doutor Altino Bondesan, 500, Parque Tecnológico, CEP 12247-016, São José dos Campos, SP. E-mail: rodolfo.mendes@cemaden.gov.br

Fernando Antônio Medeiros Marinho - Escola Politécnica, Universidade de São Paulo, Avenida Professor Almeida Prado, 83, Prédio da Engenharia Civil - PEF, Butantã, CEP 05508-900, São Paulo, SP. E-mail: fmarinho@usp.br

Mario Valerio Filho - Universidade do Vale do Paraíba - UNIVAP, Avenida Shishima Hifumi, 2911, Urbanova, CEP12244-000, São José dos Campos, SP. E-mail: mvalerio@univap.br

Artigo submetido em 1 de julho de 2015, aceito em 15 de setembro de 2015. 